\title{
Public Awareness and Practices of Pastoral and Agro Pastoral Community Towards Zoonotic Brucella Infection in Afar Regional State of North East Ethiopia
}

\author{
Angesom Hadush Desta \\ College of Veterinary Medicine, Samara University, Samara, Ethiopia
}

\section{Email address:}

meryangieboy@gmail.com

To cite this article:

Angesom Hadush Desta. Public Awareness and Practices of Pastoral and Agro Pastoral Community Towards Zoonotic Brucella Infection in Afar Regional State of North East Ethiopia. European Journal of Preventive Medicine. Vol. 3, No. 5, 2015, pp. 141-146.

doi: $10.11648 /$ j.ejpm.20150305.13

\begin{abstract}
Camel brucellosis represents a major public health hazard, which affects social and economic development in various developing countries including the pastoral areas of Ethiopia. A cross-sectional study was conducted to determine public awareness, attitude and practices of the pastoralists, agro pastoralists, animal health assistants and human health professionals towards zoonotic Brucella infection in the region using a questionnaire. A total of 168 respondents (56 individuals from each district) were interviewed. According to the logistic regression analysis, Literacy was found statistically significant $(\mathrm{P}<0.05)$ in association with awareness of the community about the disease. All respondents expressed that they consume raw milk and they did not use any protective material while handling parturient camels, removing placenta and/or other aborted materials. Only $13(7.7 \%)$ had knowledge about brucellosis and $98(58.3 \%)$ of the respondents had family members with fever of unknown cause and other signs of brucellosis. During the study, 40 animal health assistants were participated and almost all had knowledge on zoonotic Brucella infection. Moreover, out of the 112 human health professionals included in the study, only 14 (12.5\%) had knowledge on zoonotic Brucella infection. But none of them had ever diagnosed the disease in humans and the reason for the diagnosis problem was lack of facility and no attention was given to the disease. The questionnaire survey revealed that there was a knowledge gap not only in the community but also in the human health professionals about zoonotic Brucella infection in the study areas. Even though the animal health assistants had better awareness about the disease, they did not collaborate with human health professionals to create awareness to the community and to prevent the disease. Therefore, Public education on modern animal husbandry, disease prevention and risk of zoonotic Brucella infection should be imparted continuously.
\end{abstract}

Keywords: Afar, Awareness, Brucella, Ethiopia, Practice, Zoonosis

\section{Introduction}

Brucellosis is one of the major Anthropozoonotic diseases of public health importance worldwide. The disease is usually transmitted from infected animals to human by direct contact or by consumption of raw milk infected with Brucella organisms. Brucellosis is also an occupational hazard primarily of a disease of animals; it is transmitted directly and indirectly to human. Dairy workers, shepherds, veterinarians, abattoir workers and animal husbandry personnel are particularly at risk. It constitutes an uncontrolled public health problem in many developing countries (Young, 1983; Pal and Jain, 1986; Hadush and Pal, 2013).
Typically, brucellosis begins as an acute febrile illness with nonspecific flu-like signs such as fever, headache, malaise, back pain, myalgia and generalized aches (Pal, 2007). Drenching sweats can occur, particularly at night. Splenomegaly, hepatomegaly, coughing and pleuritic chest pain are sometimes seen. Gastrointestinal signs including anorexia, nausea, vomiting, diarrhea and constipation occur frequently in adults but less often in children. In many patients, the symptoms last for two to four weeks and are followed by spontaneous recovery. Others develop an intermittent fever and other persistent symptoms that typically wax and wane at 2 to 14 day intervals. Most people with this undulant form recover completely in three to twelve months. A few patients become chronically ill and relapses 
can also occur months after the initial symptoms, even in successfully treated cases (CFSPH, 2007).

Brucella organisms shed in milk, urine and vaginal discharges and thereby contaminate the environment. The infection occurs through the ingestion of unboiled milk of infected animals, contact with vaginal discharges, aborted materials, urine, faeces and blood of infected animals, through unbreached skin and mucus membrane of conjunctiva and also by inhalation (Young, 1983; Pal, 2007). Brucellosis is of particular concern in developing countries because majority of their peoples resides in rural areas with backward way of living and with close contact to livestock such as cattle, camel, sheep and goats. The global picture of brucellosis has shown resurgence especially in India and USA (Wise, 1980). Brucellosis has become a major public health concern in the Saudi Arabia, Middle East countries and sub-Saharan Africa as they have traditional pastoralist society (Cooper, 1991).

Similarly, previous serological surveys in Ethiopia showed that the disease is prevalent in different camel rearing areas of the country. Afar region is one of the camel rearing areas with huge animal population in Northeast of the country. The peoples in this region are majorly pastoralists who led nomadic way of life with their animals. The traditional animal husbandry and management system together with risky practices such as sharing dwelling with animals, handling animal products and aborted material with bare hand and consumption of raw animal products facilitated the transmission of the disease from animal to the pastoralists (Domenech, 1977; Richard, 1979; Teshome et al., 2003; Zewolda and Wereta, 2012). Hence, this study was done to assess the public awareness, attitude and practice of the pastoralists, agro pastoralists and health professionals towards zoonotic Brucella infection and current risky practices that facilitate acquiring the disease from animals in three selected districts of Afar regional state of North east Ethiopia.

\section{Material and Methods}

\subsection{Description of Study Areas}

Afar regional state is located in the Great Rift Valley, comprising semi-arid range land in northeastern Ethiopia. According to regional estimates the livestock population of Afar is about 10.12 million Tropical Livestock Unit and out of this about $859,580(8.5 \%)$ are camels. The Afar Regional State has five administrative zones, which are further subdivided into 32 districts. Pastoralism and agropastoralism are the two major livelihood ways practiced in the region. The population of the region is estimated to be about 1.2 million of which $90 \%$ are pastoralists and $10 \%$ agro-pastoral (CSA, 2007). The study was conducted in three purposively selected districts of central zone of Afar region namely; Mille, Dubti and Chifra.

\subsection{Study Population}

The population included in this study was the pastoral and agro pastoral community, animal health assistants and human health professionals found in the selected areas of Afar region, North east Ethiopia.

\subsection{Study Design}

A cross-sectional study was conducted to determine public awareness, attitude and practices of the pastoral and agro pastoral community, animal health assistants and human health professionals in relation to the public health implication of zoonotic Brucella infection in the region.

\subsection{Sampling Methods}

The study areas were selected due to the presence of high camel and human population and the habit of consuming raw camel milk. Stratified sampling method was used as pastoralists, agro pastoralists, animal health assistants and human health professionals based on their occupations. About $30 \%$ of the kebelles found in each of the districts were considered representative to the study areas and included in the study on the basis of feasibility and affordability. Hence, six kebelles each from Mille and Chifra, and five kebelles from Dubti districts were selected randomly. The number of households registered in each selected district is almost equal and the average number of agro-pastoralists inhabited in the study areas is $14 \%$ of the total population (CSA, 2007). The total sample size considered during the study was 168 respondents in which at 5\% required precision and $95 \%$ confidence interval the sample size was calculated to be 100 (Arsham, 2002) but it was increased to 168 to increase accuracy. Accordingly, a total of 168 households (56 households from each district) in which 144 from pastoral and 24 households from agro-pastoral were sampled using simple random sampling technique based on their proportion. Moreover, 40 animal health assistants and 112 human health professionals were conveniently selected based on their accessibility and willingness to participate in the study after the pilot conducted based on the availability in the districts.

\subsection{Method of Data Collection}

A separate and structured questionnaire was prepared and administered to the selected respondents, animal health assistants and human health professionals to assess the knowledge, attitude and practice of the community towards zoonotic implication of brucellosis. The questionnaire was pretested in the field to check the clarity and cultural acceptance of the ideas and relevant issues were incorporated in an open ended form. The questionnaire was properly translated to the local language 'Afarigna' and trained data collectors from the area were used for the study. Verbal consent was obtained from the respondents after the objective of the study was explained to them before starting the interview. The questionnaire for the pastoralists focused on camel management and husbandry practices, knowledge about zoonotic diseases, habit of camel 
product handling and consumption, and dead camel/aborted foeti disposal practices.

\subsection{Data Management and Statistical Analysis}

The data were summarized, cleaned, compiled, coded and stored in Microsoft Excel spread sheet and transferred to SPSS ${ }^{\circledR}$ Version 20 for statistical analysis. Descriptive and analytic statistics were computed using software SPSS $®$ Version 20. Logistic regression analysis and cross tabulation were employed to see the association of determinant factors with that of knowledge of the community about the disease. Odds ratio (OR) was used to indicate the degree of risk factor association with knowledge of the community about the disease signified by $95 \%$ confidence interval.

\section{Results}

\subsection{Questionnaire Survey on Pastoral and Agro Pastoral Community}

Table 1. Logistic regression analysis of pastoralists' awareness on zoonotic Brucella infection in Afar region, North east Ethiopia.

\begin{tabular}{|c|c|c|c|c|}
\hline \multirow{2}{*}{ Category } & \multirow{2}{*}{ № } & \multirow{2}{*}{ Awareness (\%) } & \multicolumn{2}{|l|}{ Univariate } \\
\hline & & & $\mathrm{OR}^{\mathrm{a}}\left(95 \% \mathrm{CI}^{\mathrm{b})}\right.$ & Pvalue \\
\hline \multicolumn{5}{|l|}{ Districts } \\
\hline Mille $^{*}$ & 56 & 5.36 & - & - \\
\hline Dubti & 56 & 12.50 & $0.35(0.07-1.63)$ & 0.18 \\
\hline Chifra & 56 & 5.36 & $1.05(0.17-6.60)$ & 0.96 \\
\hline \multicolumn{5}{|l|}{ Life way } \\
\hline Pastoralists ${ }^{*}$ & 144 & 7.64 & - & - \\
\hline Agro-pastoralists & 24 & 8.34 & $0.63(0.10-3.83)$ & 0.62 \\
\hline \multicolumn{5}{|l|}{ Sex } \\
\hline Male* & 140 & 7.86 & - & - \\
\hline Female & 28 & 7.14 & $0.96(0.16-5.52)$ & 0.96 \\
\hline \multicolumn{5}{|l|}{ Age } \\
\hline$<30 *$ & 32 & 6.25 & - & - \\
\hline $30-40$ & 98 & 8.16 & $1.07(0.22-5.06)$ & 0.94 \\
\hline$>40$ & 38 & 7.90 & $0.85(0.11-6.63)$ & 0.88 \\
\hline \multicolumn{5}{|l|}{ Educational level } \\
\hline Illiterate* & 133 & 3.01 & - & - \\
\hline Primary school & 35 & 25.71 & $11.74(3.08-44.75)$ & 0.00 \\
\hline \multicolumn{5}{|l|}{$\begin{array}{l}\text { Herding } \\
\text { experience }\end{array}$} \\
\hline$<10^{*}$ & 26 & 7.69 & - & - \\
\hline $10-20$ & 87 & 4.60 & $2.88(0.69-11.95)$ & 0.14 \\
\hline$>20$ & 55 & 12.73 & $2.30(0.37-14.51)$ & 0.37 \\
\hline
\end{tabular}

a: Odds ratio; b: Confidence interval; *: Reference category.

Public awareness and practices of the Pastoral and agro pastoral community towards zoonotic importance of the disease was assessed using a structured questionnaire. A total of 168 respondents (56 individuals from each district) were interviewed. Out of the 168 respondents, 140(83.3\%) were male, $28(16.7 \%)$ were female and again $133(79.2 \%)$ of them were illiterate and $35(20.8 \%)$ were literate. According to the logistic regression analysis, Literacy was found statistically significant $(\mathrm{P}<0.05)$ in association with awareness of the pastoralists about the disease (Table 1).

\subsection{Pastoral and Agro Pastoral Communities'Attitude and Practices}

About $112(66.7 \%)$ of the respondents rear camel for milk production purpose and all respondents encountered abortion cases at least once per year in their herd (Table 2).

Table 2. Camel husbandry and management practices that favor for transmission of brucellosis.

\begin{tabular}{lll}
\hline Issues raised & Response category & No of respondents (\%) \\
\hline \multirow{3}{*}{ Purpose of camel rearing } & Milk production & $112(66.7)$ \\
& Drought mitigation & $37(22.0)$ \\
& wealth & $19(11.3)$ \\
Points of mixing with & Watering & $88(52.4)$ \\
other herds and/or & Grazing & $42(25.0)$ \\
ruminants & Market & $16(9.5)$ \\
& Night resting & $8(4.8)$ \\
& Milking & $14(8.3)$ \\
Role in camel husbandry & Delivery assistance & $28(16.7)$ \\
& Mating assistance & $18(10.7)$ \\
& Treating & $12(7.1)$ \\
Means of camel health & Herding & $44(26.2)$ \\
care & Traditional healing & $101(60.1)$ \\
& of vet drugs & $42(25.0)$ \\
Presence of frequently & Vet clinics & $25(14.9)$ \\
aborting camels & yes & $168(100)$ \\
Method of managing & Sell & $109(64.9)$ \\
frequently aborting or & Slaughter & $23(13.7)$ \\
repeat breeding camel & Keep simply & $36(21.4)$ \\
Source of bull & Raise own & $118(70.2)$ \\
Selling of breeding female & Nes & $50(29.8)$ \\
breeding female & No & $44(26.2)$ \\
\hline & Disease & $124(73.8)$ \\
& Shortage of money & $11(25.0)$ \\
\hline
\end{tabular}

*some of the percentages does not sum to $100 \%(\mathrm{~N}=168$, total respondents) because all responses are not shown

Table 3. Animal products handling and consumption habits.

\begin{tabular}{lll}
\hline Issues raised & Response category & No of respondents (\%) \\
\hline Raw milk consumption & Yes & $168(100)$ \\
Raw meat consumption & Yes & $168(100)$ \\
$\begin{array}{l}\text { Type of meat consumed } \\
\text { raw }\end{array}$ & Liver & $156(92.9)$ \\
$\begin{array}{l}\text { Self protection while } \\
\text { handling parturient camels }\end{array}$ & No & $12(7.1)$ \\
$\begin{array}{l}\text { Self protection while } \\
\text { removing placenta and/or } \\
\text { other aborted material }\end{array}$ & No & $168(100)$ \\
$\begin{array}{l}\text { Method of managing } \\
\text { aborted material }\end{array}$ & Left in the field & $116(69.0)$ \\
& Given to scavengers & $40(23.9)$ \\
& Proper disposing & $12(7.1)$ \\
Care for new born & Cleaning & $54(43.2)$ \\
& Cutting the & $43(34.4)$ \\
\hline
\end{tabular}

*some of the percentages does not sum to $100 \%(\mathrm{~N}=168$, total respondents $)$ because all responses are not shown

All respondents expressed that they consume raw milk and again liver is consumed raw by most of the community. All 
respondents described that they did not use any protective material while handling parturient camels, removing placenta and/or other aborted materials (Table 3).

\subsection{Pastoral and Agro Pastoral Communities' Awareness}

Only $13(7.7 \%)$ had knowledge about brucellosis and $98(58.3 \%)$ of the respondents had family members with fever of unknown cause and other signs of brucellosis (Table 4).

\subsection{Questionnaire Survey on Animal Health Assistants and Human Health Professionals}

A separate questionnaire was administered to animal health assistants and human health professionals to evaluate the public awareness and practices of the professionals on zoonotic Brucella infection. During the study, 40 animal health assistants were participated and almost all had knowledge on zoonotic Brucella infection, transmission, treatment, control and prevention. However, all of them had never diagnosed the disease in animals (Table 5).

Moreover, out of the 112 human health professionals included in the study, only $14(12.5 \%)$ had knowledge on zoonotic Brucella infection. Out of the 14 professionals who had knowledge on the disease, majority of them knew the transmission, treatment, control and prevention methods correctly. But none of them had ever diagnosed the disease in humans and the reason for the diagnosis problem was lack of facility and no attention was given to the disease (Table 5).
Table 4. Awareness about zoonoses and zoonotic Brucella infection.

\begin{tabular}{|c|c|c|}
\hline Issues raised & Response category & № of respondents (\%) \\
\hline \multirow{3}{*}{$\begin{array}{l}\text { Know how about } \\
\text { disease transmission } \\
\text { from animal to human }\end{array}$} & Yes & $67(39.9)$ \\
\hline & No & $101(60.1)$ \\
\hline & Elders & $42(62.7)$ \\
\hline \multirow[t]{3}{*}{ Source of knowledge } & Personal observation & $20(29.8)$ \\
\hline & Training & $5(7.5)$ \\
\hline & Tuberculosis & $23(34.3)$ \\
\hline \multirow{4}{*}{$\begin{array}{l}\text { Name of known } \\
\text { zoonotic diseases }\end{array}$} & Anthrax & $15(22.4)$ \\
\hline & Rabies & $16(23.9)$ \\
\hline & Brucellosis & 13(19.4) \\
\hline & Raw meat and milk & $23(34.3)$ \\
\hline \multirow[t]{2}{*}{ Vehicle of transmission } & Contact & $28(41.8)$ \\
\hline & Inhalation & $16(23.9)$ \\
\hline \multirow{4}{*}{$\begin{array}{l}\text { Knowledge about } \\
\text { brucellosis } \\
\text { Vehicle of transmission } \\
\text { for brucellosis }\end{array}$} & Yes & $13(7.7)$ \\
\hline & No & $155(92.3)$ \\
\hline & Raw milk & $8(61.5)$ \\
\hline & Contact & $5(38.5)$ \\
\hline \multirow{4}{*}{$\begin{array}{l}\text { Treatment for } \\
\text { brucellosis } \\
\text { Family member with } \\
\text { fever of unknown cause } \\
\text { and other signs }\end{array}$} & Traditional medicine & $9(69.2)$ \\
\hline & Modern drugs & $4(30.8)$ \\
\hline & Yes & $98(58.3)$ \\
\hline & No & $70(41.7)$ \\
\hline \multirow{2}{*}{ Health center visit } & Yes & $25(25.5)$ \\
\hline & No & $73(74.5)$ \\
\hline \multirow{2}{*}{ Recovery after treatment } & Yes & $6(24.0)$ \\
\hline & No & $19(76.0)$ \\
\hline
\end{tabular}

*some of the percentages does not sum to $100 \%(\mathrm{~N}=168$, total respondents) because all responses are not shown

Table 5. Awareness about zoonotic Brucella infection and practices of animal health assistants and human health professionals.

\begin{tabular}{|c|c|c|c|}
\hline \multirow{2}{*}{ Questionnaire items } & \multirow{2}{*}{ Response category } & \multicolumn{2}{|c|}{ № of respondents (\%) } \\
\hline & & $\overline{A H A}^{\mathbf{a}}$ & HHP $^{\mathrm{b}}$ \\
\hline \multirow{2}{*}{ Know how about zoonoses } & Yes & $40(100)$ & $86(76.8)$ \\
\hline & No & - & $26(23.2)$ \\
\hline \multirow{3}{*}{ Knowledge about zoonotic brucellosis } & Yes & $40(100)$ & $14(12.5)$ \\
\hline & No & - & $98(87.5)$ \\
\hline & Raw milk & $40(100)$ & $14(100)$ \\
\hline \multirow[t]{2}{*}{ Vehicle of transmission to humans ${ }^{*}$} & Raw meat & $23(57.5)$ & $8(57.1)$ \\
\hline & Contact & $32(80)$ & $4(28.6)$ \\
\hline \multirow{3}{*}{ Treatment of brucellosis in human } & Antibiotics & $34(85)$ & $10(71.4)$ \\
\hline & No knowledge & $6(15)$ & $4(28.6)$ \\
\hline & Avoiding raw milk & $40(100)$ & $14(100)$ \\
\hline \multirow{2}{*}{ Control and prevention techniques* } & Avoiding raw meat & $23(57.5)$ & $8(57.1)$ \\
\hline & Avoiding contact & $32(80)$ & $4(28.6)$ \\
\hline Attitude of diagnosing brucellosis & No & $40(100)$ & $14(100)$ \\
\hline \multirow{3}{*}{ Reason for no diagnosis* } & No facility & $30(75)$ & $14(100)$ \\
\hline & No attention & $40(100)$ & $14(100)$ \\
\hline & High & $14(35)$ & $4(28.6)$ \\
\hline \multirow[t]{2}{*}{ Risk of brucellosis to human health } & Medium & $21(52.5)$ & $6(42.8)$ \\
\hline & Low & $4(10)$ & $4(28.6)$ \\
\hline \multirow{2}{*}{ Responsible body to control the disease* } & Veterinarians & $40(100)$ & $10(71.4)$ \\
\hline & Human Health professionals & $28(70)$ & $14(100)$ \\
\hline
\end{tabular}

a: Animal health assistants; $b$ : Human health professionals; *: The percentages do not some to $100 \%(a=40, b=112$ total respondents each) because more than one answer was possible.

\section{Discussion}

Brucellosis is considered by the Food and Agriculture Organization (FAO), the World Health Organization (WHO) and the Office International des Epizooties (OIE) as one of the most widespread zoonoses in the world (Schelling et al.,
2003). According to OIE, it is the second most important zoonotic disease in the world accounting for the annual occurrence of more than 500,000 cases (Pappas et al., 2006). As a result of the traditional and nomadic way of living, consumption of raw animal products, sharing dwelling with their animals and poor management practices, the pastoral 
community found in Ethiopia are highly prone to this disease. Hence, a cross-sectional study was conducted in three selected districts of Afar region to determine the public awareness, attitude and practice of the pastoral and agro pastoral community and health professionals in these areas.

The questionnaire survey on pastoralists and agro pastoralists showed that literate pastoralists and agro pastoralists had better awareness than illiterate which was statistically significant $(\mathrm{P}<0.05)$ association. Even though, it was not statistically significant $(\mathrm{P}>0.05)$ agro-pastoralists, and pastoralists with $>20$ years herding experience had better awareness about zoonotic Brucella infection in the study areas. This result showed that education plays a great role in developing awareness on zoonotic diseases.

The respondents included in the questionnaire survey have provided information regarding the management and husbandry practices, handling and consumption behaviors and knowledge on zoonotic Brucella infection. Accordingly, majority of the pastoralists kept camel for milk production purpose and there is a chance of mixing their camel herds with other herds and/or ruminants in watering points, pasture, night resting, and market and during migration. All respondents come across with frequently aborting she-camels and sell such animals in the market. High number of respondents had no detailed and accurate knowledge about zoonotic brucellosis. This low awareness is a limiting factor if prevention and control strategies are to be implemented and it also predisposes the community for the disease. Elders were the main source of knowledge which showed that there was shortage of public health education rendered to the community.

According to the questionnaire survey, the most important practices potentially supporting the transmission of the zoonotic diseases in the study area were bare hand management of newborn, aborted fetus and retained fetal membrane and consumption of raw milk as well as raw liver. Aborted fetuses and placenta thrown in the field, though rarely destroyed were likely to play a role on livestock and human brucellosis. Moreover, the maintenance with in herd and selling of frequently aborting she-camels to others and use of common bull for mating serve as a source of disease transmission in the area.

The presence of relatively high prevalence of brucellosis in camels, unrestricted movement of animals with in the area, raw milk consumption behavior of the community and low awareness of the disease in particular and zoonoses in general may result in high degree of transmission of the disease to human in the area (Abbas and Agab 2002). Moreover, majority of the respondents had family members with fever of unknown cause and other signs of brucellosis and some of them visited health centers. But, the illness was not relieved even after taking the medicines given by the health professionals. The disease in man may be misdiagnosed due to the prevailing malaria infections in dry areas (Abou-Eisha, 2000; El-Ansary et al., 2001). There is also a $15 \%$ prevalence report of human brucellosis in selected districts of Afar region by Zewolda and Wereta
(2012) which supports the probability of Brucella infection in humans in the present study area too.

The questionnaire survey on animal health assistants and human health professionals showed that animal health assistants (100\%) had good knowledge on transmission, treatment, control and prevention of the disease than the human health professionals $(12.5 \%)$. However, both stream of professionals never diagnosed the disease in their health centers and they expressed that there was no facility for diagnosis and no attention was given to the disease both in the animal and human health because the risk of the disease to human health was not understood. This result showed that there was less awareness about the disease in human health professionals and there was no trial of educating the community about the disease prevention and control. Finally, both animal and human health professionals expressed that both professionals were responsible on educating the community and on controlling and preventing the disease from transmitting from animal to human and from one area to another areas.

\section{Conclusion}

The questionnaire survey revealed that there was a knowledge gap not only in the pastoralists and agro pastoralists but also in the human health professionals about the zoonotic Brucella infection in the study areas. Even though the animal health assistants had better awareness about the disease, they did not collaborate with human health professionals to create awareness to the community and to prevent the disease. Traditional husbandry and poor management practices, mixing with other animals and unrestricted movement of camels were thought to support spread of the disease in the study areas. In addition to this, lack of knowledge on zoonoses and consumption of raw milk together with handling of parturient animal products with bare hand facilitated transmission of the disease to the pastoralists and agro pastoralists. Therefore, Public education on modern animal husbandry, disease prevention and risk of zoonotic diseases should be imparted continuously. A joint program on prevention and control of the disease in both the pastoralists and agro pastoralists and their animals should be formulated and implemented by an interdisciplinary one-health collaboration between veterinarians, human health professionals and policy makers in a more effective approach to aware and educate the communities.

\section{References}

[1] Abbas, B. and Agab, H. (2002): A review of camel Brucellosis J. Prev. Vet. Med., 55:47-56.

[2] Abou-Eisha, A. M. (2000): Brucellosis in camels and its relation to public health. Asuit Vet. Med. J., 44:54-64.

[3] Arsham H., Questionnaire Design and Surveys Sampling, SySurvey: The Online Survey Tool, 2002.

[4] CSA (Central Statistical Agency) (2007): Human and animal population census in Afar region. Addis Ababa, Ethiopia. 
146 Angesom Hadush Desta: Public Awareness and Practices of Pastoral and Agro Pastoral Community Towards Zoonotic Brucella Infection in Afar Regional State of North East Ethiopia

[5] CFSPH (Center for Food Security and Public Health) (2007): Brucellosis in human. College of Veterinary Medicine, Iowa State University, Ames, Iowa, Pp. 1-13.

[6] Cooper, C. W. (1991): The epidemiology of human brucellosis in a well defined urban population in Saudi Arabia. J. Trop. Med. Hyg., 94:416-422.

[7] Domenech, J. (1977): Brucellosis of dromedaries in Ethiopia. Rev. Elev. Med. Vet. Pays. Trop., 30:141-142.

[8] El-Ansary, E. H., Hamad, B. R. and Karom, G. O. (2001): Brucellosis among animals and humans in contacts in eastern Sudan. Saudi Med. J., 22:577-579.

[9] Hadush, A. and Pal, M. (2013): Brucellosis - An infectious reemerging bacterial zoonosis of global importance. Int. J. Livest. Res., 3:28-34.

[10] Pal, M. and Jain, H. S. (1986): Anthropozoonotic role of Brucella abortus. Int. J. Zoonoses, 13:246-248.

[11] Pal, M. (2007): Zoonoses. $2^{\text {nd }}$ ed. Satyam publishers. Jaipur, India, Pp. 98-99.

[12] Pappas, G., Papadimitriou, P., Akritidis, N., Christou, L. and Tsianos, V. (2006): The new global map of human brucellosis. Lancet Infect. Dis., 6:91-99.
[13] Richard, L. K. (1979): Ingestion and intracellular survival of Brucella abortus in human and bovine polymorphonuclear leukocytes. Infect. Immun., 46:224-230.

[14] Schelling, E., Diguimbaye, C., Nicolet, J., Boerlin, P., Tanner, M. and Zinsstag, J. (2003): Brucellosis and Q fever seroprevalence of nomadic pastoralists and their livestock in Chad. Prev. Vet. Med., 61:279-293.

[15] Teshome, H., Molla, B. and Tibbo, M. (2003): A seroprevalence study of camel brucellosis in three camelrearing regions of Ethiopia. Trop. Anim. Health Prod., 35:381389.

[16] Wise, R. I. (1980): Brucellosis in the United States. Past, present and future. J. Am. Med. Assoc., 24:2318-2322.

[17] Young, E. J. (1983): Human brucellosis. Rev. Infect. Dis., $5: 821-842$.

[18] Zewolda, S. W. and Wereta, M. H. (2012): Seroprevalence of Brucella infection in camel and its public health significance in selected districts of Afar region, Ethiopia. J. Environ. Occupat. Sci., 1: 91-98. 